\title{
Social inequalities in reception of social welfare support: A population based twin study
}

\author{
Eivind Ystrom ${ }^{1,2,3}$, Ragnhild Ørstavik ${ }^{1,4}$, Ted Reichborn-Kjennerud ${ }^{1,5}$ and Fartein Ask Torvik ${ }^{1}$ \\ 1) Norwegian Institute of Public Health, Domain for Mental and Physical Health, Oslo, Norway \\ 2) Section of Health, Developmental and Personality Psychology, Department of Psychology, University of Oslo, Oslo, Norway \\ 3) PharmacoEpidemiology and Drug Safety Research Group, School of Pharmacy, University of Oslo, Norway \\ 4) The Norwegian Medical Association, Oslo, Norway \\ 5) Institute of Clinical Medicine, University of Oslo, Oslo, Norway \\ Correspondence: Eivind Ystrom, Norwegian Institute of Public Health, P.O. Box 4404 Nydalen, NO-0403 Oslo, Norway \\ Email: eivind.ystrom@fhi.no
}

\begin{abstract}
Social welfare support runs in families. Recent studies using Nordic registry data have found individual differences in genetic factors to be of substantial importance for medical benefits. However, to date there has been no genetically informative studies on receiving social welfare support. To prevent young adults from dropping out of the work life and become recipients of social welfare support, it is of substantial interest to clarify to what extent the familiarity of social welfare support is due to genetic or social differences between families. We used data from the Historical-Event Database on 7,698 Norwegian twins born 1967-1979 to estimate the relative contribution of genetic factors, the effective familial environment (i.e. the "shared environment"), and individual-specific environmental factors. We found that the two forms of familial risk, genetic and shared environmental, explained $39 \%$ and $45 \%$, respectively, of the risk for receiving social welfare support among young Norwegian twins. Only $17 \%$ of the variance in risk factors could be explained by individual-specific risk factors. It appears that risk for receiving social welfare support can to a great extent be explained by environmental differences between families. Therefore prevention strategies targeting social inequalities between families would indeed be effective. Furthermore, genetic risk factors are also important in explaining risk for receiving social welfare support. These effects could be mediated through heritable traits related to substance abuse, psychiatric disorders, and personality. Individual-specific risk factors were of very little importance. Hence, with regard to receiving social welfare support, family matters.
\end{abstract}

This is an open access article distributed under the Creative Commons Attribution Licence, which permits unrestricted use, distribution, and reproduction in any medium, provided the original work is properly cited.

\section{INTRODUCTION}

It is commonplace to think of Norway as an egalitarian society where everyone has equal rights and equal access to the various welfare schemes. Nevertheless, important life outcomes, such as educational attainment, are strongly influenced by family background, even when the effects of genetic factors are accounted for (1). This may also hold for other aspects of the welfare state. In the present study, we explore whether reception of social welfare support is influenced by family background, in addition to individual exposures and genetic predispositions.

In Norway and other countries, the government provides social welfare support (Norwegian: "økonomisk sosialhjelp") for individuals who are not able to provide for themselves economically. Social welfare support is a temporary welfare scheme, where the intention is that recipients should be able to provide for themselves as soon as possible. It is given as a last resort for economic subsistence, and is only paid after all other possible economic options have been evaluated (2). This means, for instance, that social welfare benefits are not given if an individual qualifies for the more generous unemployment benefits, or if an individual has savings. Being a last resort, the payouts of social welfare support are less than other welfare schemes, and are intentionally kept at a subsistence minimum.

Although social welfare support is indeed temporary for many of its recipients, some individuals stay on social welfare support or other kinds of welfare schemes over long periods of time (3). Similar effects are even seen across generations, where children of welfare recipients on average do worse than other children on a wide range of outcomes, including a higher risk of being welfare recipients themselves (4). In a sense, receiving welfare seems to "run in families". The reasons for this have not been clarified.

Using twin studies, it is possible to approach the etiology of risk factors, by dividing the variance into three sources: additive genetic effects, individualspecific environment, and the environment that family members share, but which varies between families. The latter include, by definition, only environmental factors that make twins in a pair similar, whether be it intrauterine factors, upbringing or influence from peers or teachers. Other medical welfare schemes, such as long-term sick leave and disability pensioning, has been found to be affected by genetic factors, but not by shared environment, at least not at levels high enough to be statistically significant (5-9). These benefits are medical benefits, and are hence caused by medical dis- 
orders which are again partly or substantially influenced by genes. At the same time, sick leave and disability pensioning is affected by many factors besides health (10). Sick leave also requires that one has a job, or is otherwise eligible for employment. These differences imply that the mechanism leading to social welfare support may be substantially different from those leading to medical welfare benefits. To the best of our knowledge, there is to date no genetically informative study on why welfare aggregate in certain families.

Social welfare support is, like all human aspects that vary within a population, likely to be at least partially heritable (11). It follows that being a recipient of social welfare support, if correlated with any heritable trait, such as personality, education, intelligence and so on, will also be heritable. It is, however, less commonplace to find large effects of shared environment in human traits. Whereas most outcomes show small influences of shared environment, knowing which variables that are affected by shared environment is important, as this would indicate areas of the society where all individuals are not treated equally or not have the same opportunities. Although shared environment does not equal family environment since twins also share environments distinct from their parents (e.g. common friends and school), it is likely that much of environmental influence that makes twins similar stem from their shared upbringing. In a way, twin studies can be used to test the egalitarianism of societies, i.e., to test whether it does not only matter who you are, but also who your family is. If everyone is treated equally, the family-specific environmental variance (i.e. the shared environmental variance) will decrease, implying that the relative contributions of genetic factors and individual-specific environment increases. As economic resources are often aggregated in families, social welfare support is a likely candidate to have stronger effects of shared environment. In addition, the stigma of applying for social welfare support may be less hard to bear if one has been "desensitized" by having family members on social welfare support.

In the present study, we therefore investigate to what degree receiving social welfare support is associated with genetic and shared environmental factors.

\section{MeThodS}

\section{Sample and assessment}

The sample for the current study originated from the Norwegian Institute of Public Health Twin Panel (NIPHTP). Twins born between 1967 and 1979 were invited to take part in a large questionnaire study in 1998 and consented to linking with administrative registries from Statistics Norway including social welfare benefits from 1998 to 2008 .

Out of 12,700 invited twins, 8,045 (63\%) responded after one reminder. Among these, 7,710 twins were linked to sick leave data, while 335 withdrew from the study. Further 12 twins were excluded due to lack of data on zygosity. The sample of 7,698 twins included 3,108 complete pairs (492 monozygotic (MZ) male, 354 dizygotic (DZ) male, $759 \mathrm{MZ}$ female, $607 \mathrm{DZ}$ female, and 896 opposite sex twin pairs) and 1,482 singletons.

Zygosity was initially determined using questionnaire items previously shown to correctly classify more than $97 \%$ of the twin pairs (Magnus et al., 1983), followed by DNA analyses on a subgroup of the sample. The discrepancy between classification based on the questionnaire and DNA markers implied an expected misclassification rate of approximately $2 \%$ for the whole sample, which is unlikely to bias our results (Neale, 2003).

The NIPHTP is thoroughly described elsewhere (Nilsen et al., 2012).

\section{Ethics}

The linkage of data from NIPHTP with registries at Statistics Norway was approved by the Regional Committee for Medical and Health Research Ethics.

\section{Measures}

Social welfare support

The Historical-Event Database contains data for the entire population (1992 and onwards) regarding economic activity, including social security benefits. Thus, we had information on who received social welfare support, and when. From this information, we constructed two variables: a dichotomous variable, "has ever received social welfare support" vs. not, and a time-to-event variable where individuals were censored at the age they first received social welfare support, or, if they never received social welfare support, at the age they had when the study ended in 2008.

\section{Statistical analyses}

In the classic twin design (12), individual differences in liability are assumed to arise from additive genetic (A), shared environmental (C), and non-shared environmental (E) sources. As MZ twins share all, and DZ twins share on average half of their segregating genes, A would tend to make MZ twins correlate twice as highly as DZ twins. C is defined as environmental factors that contribute to similarity between twins, and is assumed to have an equal effect on co-twin similarity in $\mathrm{MZ}$ and $\mathrm{DZ}$ twins. $\mathrm{E}$ is by definition not shared between twins in a pair and contributes to twin differences. E also contains measurement error. The influence of each of these factors on the variables can be estimated using structural equation modeling (SEM) (12).

The models were fitted using the Full Information Maximum Likelihood (FIML) with a logit link as estimation procedure to raw data in Mplus (13). The raw data method utilizes data from both complete and incomplete pairs, which, under the missing at random assumption, decrease bias due to non-response. All twins with known zygosity were included in the analyses. We used the Akaike Information Criterion (AIC) as an index of parsimony (Akaike, 1987). Models with 


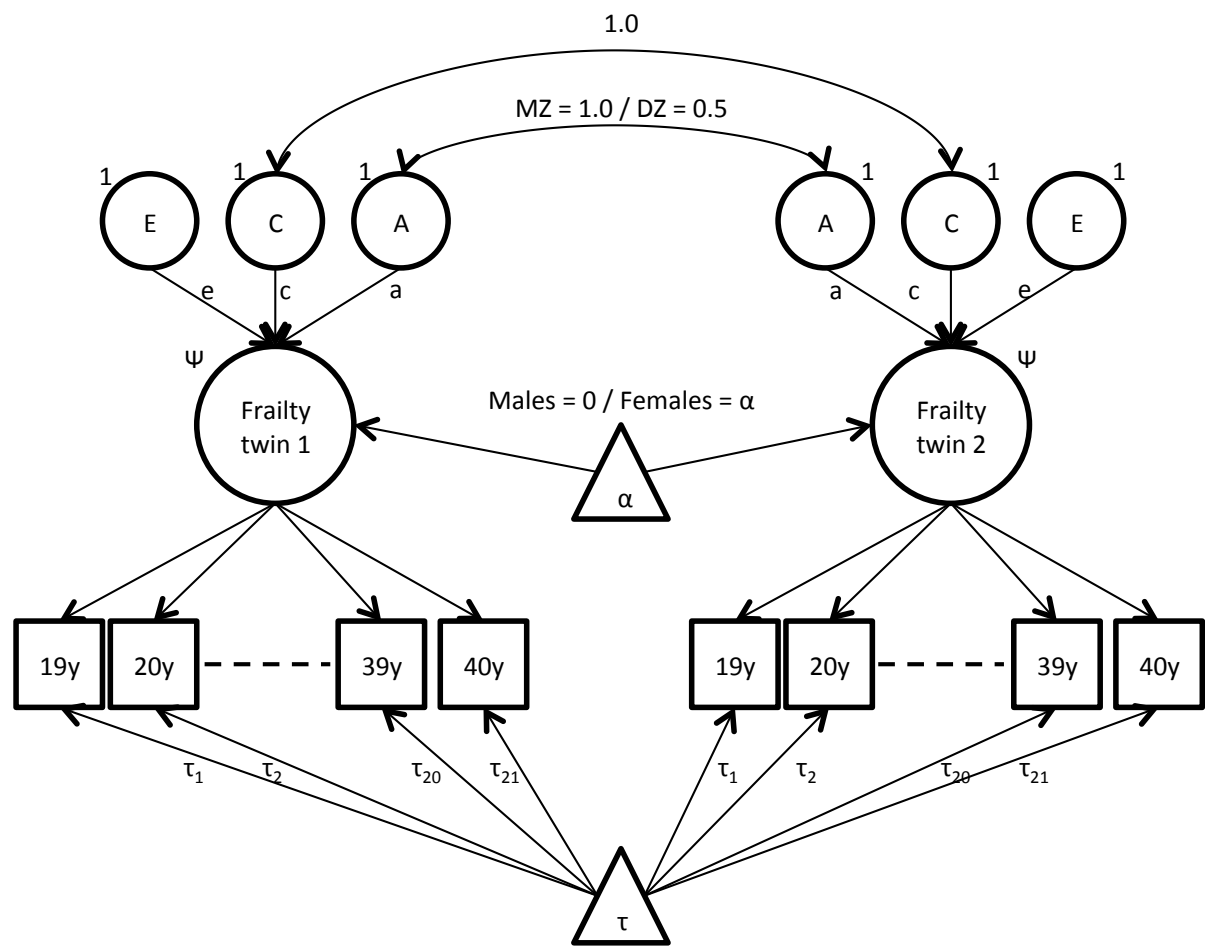

Figure 1. Pathmodel for biometric discrete-time survival analysis. Circles represent latent variables, squares represent observed variables, and triangles represent means or thresholds. Double headed arrows represent covariances, and single headed arrows represent regression coefficients. $\mathrm{MZ}=$ monozygotic twins and $\mathrm{DZ}=$ dizygotic twins. A, C, and $\mathrm{E}$ denotes additive genetic, shared environmental, and individual-specific environmental effects, respectively. Small letter a, c, and e denotes respective path coefficients. Psi, the frailty variance, is constrained to be equal to $\mathrm{a}^{\wedge} 2+\mathrm{c}^{\wedge} 2+\mathrm{e}^{\wedge} 2$. The latent frailty distribution is normal. Alpha is the mean of the latent frailty distribution, and is zero in males and estimated in females. Tau denotes thresholds. Each age (i.e. year 19 to 40) have a unique threshold. Thresholds are equal in males and females, and sex differences in hazard rates are modeled by differences in latent frailty means (i.e. alpha).

low AIC value are preferred. If the difference in AIC is negative, the simpler, more restricted model is preferred.

Since the participants were not beyond the age where they could receive social welfare support, the data was censored. We used a general latent variable approach to discrete-time survival analysis of nonrepeatable events (i.e. first time reception of social welfare support) (14). The biometric frailty model is depicted in Figure 1. Variance in risk for social welfare support is modeled by a latent factor that is correlated across twins. This model has earlier been applied to Finnish disability data in twins (9). Further details of the model are described in the legends of Figure I. We compare the results from the biometric descrete time survival analysis to the much used liability threshold model to explore the impact of censoring in the data. Censoring is a form of measurement error, and would inflate the E component in the liability threshold model.

\section{RESULTS}

In Figure 2 we present the year-by-year percent (i.e. incidence) of the participants receiving social welfare support. The incidence of social welfare support was highest in the youngest age groups (close to five percent per year), and fell in a linear manner towards age 40 (approximately 1.5 percent per year).
By comparing model fit, we tested for qualitative genetic sex differences (i.e. genes at different loci having effect across sexes) and quantitative genetic sex differences (i.e. genes at same loci having different effect across the sexes. The best fitting model was one with no differences in etiology across sexes (AIC= -6.4). By applying the much used liability-threshold model we found individual differences, or variance, in risk for receiving social welfare to be $36 \%$ due to additive genetic effects, $38 \%$ due to shared environmental effects, and $26 \%$ due to individual-specific environmental effects (Table 1). By accounting for censoring using the correlated, or biometric, frailty model we found individual differences in risk for receiving social welfare support to be more familial with additive genetic effects explaining $39 \%$ of the variance, shared environmental effects explaining $45 \%$ of the variance, and individual-specific environmental effects explaining $17 \%$ of the variance (Table 1 ).

\section{Discussion}

In the present study, we found that environment shared by twins, often referred to as shared, or familial, environment, constitute the strongest influence on reception of social welfare support (i.e. $45 \%$ of the total variance in risk). In addition we found a somewhat lower effect of genetic risk factors (i.e. $39 \%$ of the 


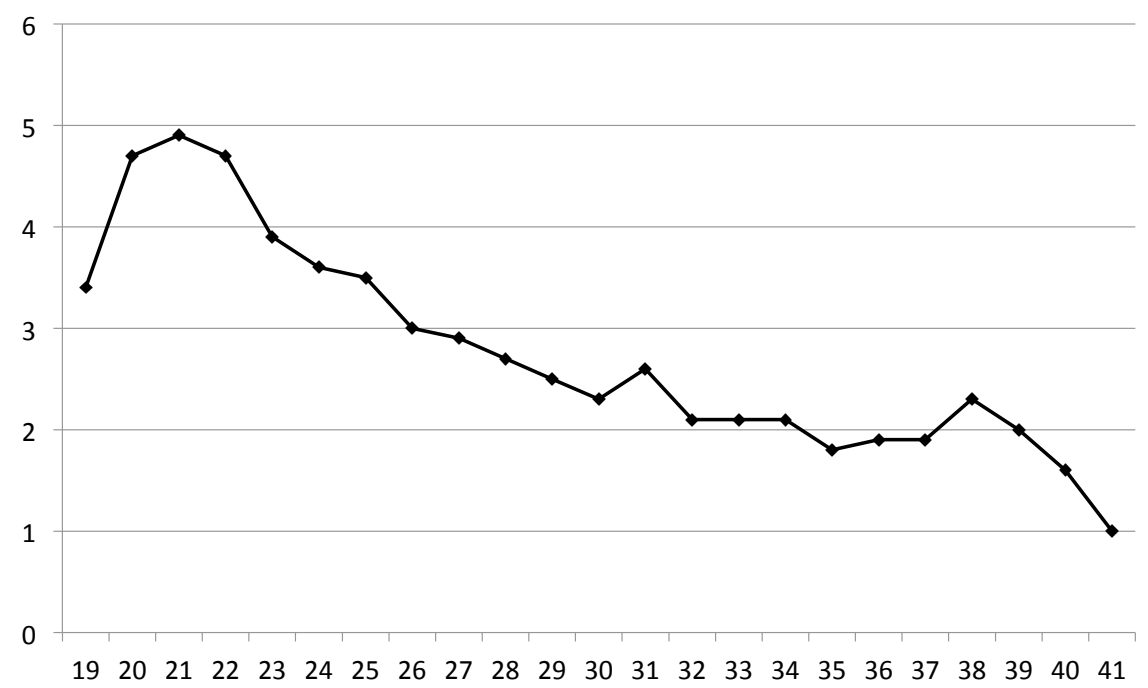

Figure 2. Percent receiving social welfare support from age 19 to 41 .

Table 1. Estimates for additive genetic (A), shared environmental (C), and individual-specific environmental (E) effects on receiving social welfare support among young Norwegian twins.

\begin{tabular}{|c|c|c|c|c|c|c|}
\hline & \multicolumn{3}{|c|}{ Correlated frailty } & \multicolumn{3}{|c|}{ Liability-threshold } \\
\hline & Estimate & $95 \% \mathrm{CI}$ & S.E. & Estimate & $95 \% \mathrm{CI}$ & S.E. \\
\hline A & $39 \%$ & $12-65 \%$ & $14 \%$ & $36 \%$ & $10-62 \%$ & $13 \%$ \\
\hline $\mathrm{C}$ & $45 \%$ & $22-67 \%$ & $12 \%$ & $38 \%$ & $17-60 \%$ & $11 \%$ \\
\hline $\mathrm{E}$ & $17 \%$ & $9-25 \%$ & $4 \%$ & $26 \%$ & Not estin & \\
\hline
\end{tabular}

* Standard errors for individual-specific environmental effects are not estimateable using full-information maximum likelihood in Mplus.

total variance in risk). Last, we found environmental factors not shared by siblings the same age growing up in the same family to only explain a small portion of the variance in risk (i.e. $17 \%$ ).

Erik Turkheimer has put forward three laws of behavior genetics: §1, all human traits are heritable. §2, the effect of being raised in the same family is smaller than the effect of genes. $\S 3$, a substantial portion of the variation in complex human behavioral traits is not accounted for by the effects of genes or families (11). If we for the sake or argument set aside the question on to what extent risk for receiving social welfare support is a complex human behavioral trait, our current findings are in clear violation with both $\S 2$ and $\S 3$. One putative explanation to this is that risk for receiving social welfare support is an amalgam of complex human behavioral traits (e.g. alcohol abuse, drug abuse, psychosis, low intelligence, personality, and personality disorders) that are following Turkheimer's rules, and social structures segregating families into low and high risk strata, influenced by shared environmental factors (e.g. economic savings and parents helping out).

Individual-specific environmental factors are, as predicted by Turkheimer's $\S 3$, of large effect in studies of human traits and behaviors (15). These factors are not well understood, and could be said to represent ideographic events across the life course that are challenging to measure in a systematic, or nomothetic (i.e. relating to the study of general laws of nature), way across individuals $(16,17)$. In our approach we study time-invariant risk factors (i.e. factors with equal effect at all time points), while individual specific environmental factors for traits such as negative and positive affect have been shown to not even be stable across matter of minutes (18).

The remarkably high effect of shared environment has some implications. If a society is entirely egalitarian and everyone is treated equally, an outcome will be a function of genetic factors and events affecting each individual, whereas family background will be of no importance. If we find that family background plays a role, this either indicates unequal access to welfare, or that family-specific norms play a role in events leading to welfare reception (sometimes called "social contagion"). If there is a correlation between the genetic risk in a family (e.g. susceptibility for drug addiction) and the shared environment of a family, this gene-environment correlation will be attributed to the shared environmental effects in the classical twin design. This is not an error in the classical twin design, given that it is a shared environmental effect, but it illuminates how genetic risk in families is mediated (i.e. either as a direct genetic transmission or mediated 
through the provided rearing environment shared by siblings). A correlation between the rearing environment and genetic risk for traits leading to severe occupational difficulties is arguably not implausible. It is possible to estimate such correlations between familial genetic risk and familial environment by using extended kinship designs (19-23). Registry-based data are available in Scandinavian countries. Future studies should therefore use extended kinship designs to estimate possible gene-environment correlations.

Being the recipient of social welfare support is stigmatizing, and receiving this kind of payout directly implies low socioeconomic status in terms of income and occupation, and indirectly implies low educational attainment. Social inequalities are therefore a central aspect of social welfare support. Therefore, in terms of prevention, social welfare support is a policy relevant to phenomena that are indeed directly caused by social differences between families.

Our results are also interesting in the light of what has previously been found in the above mentioned studies of genetic and environmental influences on medical benefits (sickness absence and disability pensioning) (7). If the effect of shared environment on social welfare is indeed much larger than its effect on medical benefits, it seems reasonable to suggest that social influence (especially parental social influence) might be much more relevant for social than for medical benefits. This is important as social influence, including influence from parents, has been suggested to impact substantially on who become recipients of medical benefits (24). Twin studies are often, right- fully, criticized for being underpowered in their ability to uncover shared environmental effects. The fact that we find substantial shared environmental effects on being a recipient of social, but not medical (7), benefits in the same sample is therefore also sheds a reassuring light on our previous findings.

Heritability does not imply absolute determinism. Heritability is the correlation between genetic factors and an observed phenotype. If the variable of interest is correlated with anything influenced by genes, then our variable of interest will also be heritable. A review of all published twin studies indicated that genetic factors accounted for approximately $50 \%$ of the variance, across phenotypes, with only small contributions from shared environment for most phenotypes (25). For example, lung cancer is to some extent heritable (26); however, so is cigarette smoking (27). In fact, the gene most associated with lung cancer is a nicotine receptor gene (28). Putative factors related to receiving social welfare support are heritable: Alcohol use disorders $(29,30)$, drug use disorders (31), and personality disorders (32-34), which can all be prevented or treated.

\section{CONCLUSION}

The environment shared between family members constitutes the strongest influence on reception of social welfare support. However, reception of social welfare support is also influenced by genetic factors. With regard to this welfare scheme, it does not just matter who you are, but also who your family is.

\section{REFERENCES}

1. Heath AC, Berg K, Eaves LJ, Solaas MH, Corey LA, Sundet J, et al. Education policy and the heritability of educational attainment. Nature 1985; 314 (6013): 734-6.

2. NAV. Financial assistance: NAV; 2011 [updated November 30 2015; cited 2016 March 4]. Available from: https://www.nav.no/en/Home/Benefits+and+services/Relatert+informasjon/financial-assistance-socialassistance.

3. Dahl G. Langtidsmottakere av økonomisk sosialhjelp. Oslo: Statistisk sentralbyrå, 2006.

4. Coelli MB, Green DA, Warburton WP. Breaking the cycle? The effect of education on welfare receipt among children of welfare recipients. J Public Econ 2007; 91 (7-8): 1369-98.

5. Torvik FA, Gjerde LC, Roysamb E, Tambs K, Kendler KS, Czajkowski NO, et al. Genetic and environmental contributions to the relationship between internalizing disorders and sick leave granted for mental and somatic disorders. Twin Res Hum Genet 2014; 17 (4): 225-35.

6. Gjerde LC, Roysamb E, Czajkowski N, Knudsen GP, Ostby K, Tambs K, et al. Personality disorders and long-term sick leave: A population-based study of young adult Norwegian twins. Twin Res Hum Genet 2014; 17 (1): 1-9.

7. Gjerde LC, Knudsen GP, Czajkowski N, Gillespie N, Aggen SH, Roysamb E, et al. Genetic and environmental contributions to long-term sick leave and disability pension: A population-based study of young adult Norwegian twins. Twin Res Hum Genet 2013; 16 (4): 759-66.

8. Narusyte J, Ropponen A, Silventoinen K, Alexanderson K, Kaprio J, Samuelsson A, et al. Genetic liability to disability pension in women and men: a prospective population-based twin study. PLoS One 2011; 6 (8).

9. Harkonmaki K, Silventoinen K, Levalahti E, Pitkaniemi J, Huunan-Seppala A, Klaukka T, et al. The genetic liability to disability retirement: A 30-year follow-up study of 24,000 Finnish twins. PLoS One 2008; 3 (10).

10. Ostby KA, Czajkowski N, Knudsen GP, Ystrom E, Gjerde LC, Kendler KS, et al. Personality disorders are important risk factors for disability pensioning. Soc Psychiatry Psychiatr Epidemiol 2014; 49 (12): 2003-11. 
11. Turkheimer E. Three laws of behavior genetics and what they mean. Curr Dir Psychol Sci 2000; 9 (5): 160-4.

12. Neale M, Cardon L. Methodology for genetic studies of twins and families. Dordrecht: Kluwer Academic Publishers, 1992.

13. Muthén LK, Muthén BO. Mplus user's Guide. Los Angeles, CA: Muthén \& Muthén, 2012.

14. Muthen B, Masyn K. Discrete-time survival mixture analysis. J Educ Behav Stat 2005; 30 (1): 27-58.

15. Smith GD. Epidemiology, epigenetics and the 'Gloomy Prospect': embracing randomness in population health research and practice. Int J Epidemiol 2011; 40 (3): 537-62.

16. Kendler KS, Halberstadt LJ. The road not taken: life experiences in monozygotic twin pairs discordant for major depression. Mol Psychiatry 2013; 18 (9): 975-84.

17. McAdams DP, Pals JL. A new big five - Fundamental principles for an integrative science of personality. Am Psychol 2006; 61 (3): 204-17.

18. Burt SA, Klahr AM, Klump KL. Do Non-shared environmental influences persist over time? An examination of days and minutes. Behav Genet 2015; 45 (1): 24-34.

19. Coventry WL, Keller MC. Estimating the extent of parameter bias in the classical twin design: A comparison of parameter estimates from extended twin-family and classical twin designs. Twin Res Hum Genet 2005; 8 (3): 214-23.

20. Keller MC, Medland SE, Duncan LE. Are extended twin family designs worth the trouble? A comparison of the bias, precision, and accuracy of parameters estimated in four twin family models. Behav Genet 2010; 40 (3): 377-93.

21. D'Onofrio BM, Lahey BB. Biosocial influences on the family: A decade review. J Marriage Fam 2010; 72 (3): $762-82$.

22. D'Onofrio BM, Lahey BB, Turkheimer E, Lichtenstein P. Critical need for family-based, quasi-experimental designs in integrating genetic and social science research. Am J Public Health 2013; 103 (Suppl 1): S46-55.

23. Narusyte J, Neiderhiser JM, D'Onofrio BM, Reiss D, Spotts EL, Ganiban J, et al. Testing different types of genotype-environment correlation: An extended children-of-twins model. Dev Psychol 2008; 44 (6): 1591-603.

24. Kristensen P, Bjerkedal T, Brevik JI. Long term effects of parental disability: A register based life course follow-up of Norwegians born in 1967-1976. Norsk Epidemioogil 2004; 14 (1): 97-105.

25. Polderman TJ, Benyamin B, de Leeuw CA, Sullivan PF, van Bochoven A, Visscher PM, et al. Meta-analysis of the heritability of human traits based on fifty years of twin studies. Nat Genet 2015; 47 (7): 702-9.

26. Mucci LA, Hjelmborg JB, Harris JR, Czene K, Havelick DJ, Scheike T, et al. Familial risk and heritability of cancer among twins in Nordic countries. JAMA 2016; 315 (1): 68-76.

27. Li MD, Cheng R, Ma JZ, Swan GE. A meta-analysis of estimated genetic and environmental effects on smoking behavior in male and female adult twins. Addiction 2003; 98 (1): 23-31.

28. Furberg H, Kim Y, Dackor J, Boerwinkle E, Franceschini N, Ardissino D, et al. Genome-wide meta-analyses identify multiple loci associated with smoking behavior. Nat Genet 2010; 42 (5): 441-U134.

29. Ystrom E, Reichborn-Kjennerud T, Aggen SH, Kendler KS. Alcohol dependence in men: reliability and heritability. Alcohol Clin Exp Res 2011; 35 (9): 1716-22.

30. Ystrom E, Kendler KS, Reichborn-Kjennerud T. Early age of alcohol initiation is not the cause of alcohol use disorders in adulthood, but is a major indicator of genetic risk. A population-based twin study. Addiction 2014; 109 (11): 1824-32.

31. Ystrom E, Reichborn-Kjennerud T, Neale MC, Kendler KS. Genetic and environmental risk factors for illicit substance use and use disorders: Joint analysis of self and co-twin ratings. Behav Genet 2014; 44 (1): 1-13.

32. Reichborn-Kjennerud T, Czajkowski N, Ystrom E, Orstavik R, Aggen SH, Tambs K, et al. A longitudinal twin study of borderline and antisocial personality disorder traits in early to middle adulthood. Psychol Med 2015; 45 (14): 3121-31.

33. Kendler KS, Aggen SH, Neale MC, Knudsen GP, Krueger RF, Tambs K, et al. A longitudinal twin study of cluster A personality disorders. Psychol Med 2015; 45 (7): 1531-8.

34. Gjerde LC, Czajkowski N, Roysamb E, Ystrom E, Tambs K, Aggen SH, et al. A longitudinal, populationbased twin study of avoidant and obsessive-compulsive personality disorder traits from early to middle adulthood. Psychol Med 2015; 45 (16): 3539-48. 